\title{
OSOBINE LIČNOSTI KAO PREDIKTORI ZADOVOLJSTVA POSLOM ${ }^{1}$
}

\section{Jelena Matanović ${ }^{2}$}

Odsek za psihologiju, Filozofski fakultet Novi Sad

\begin{abstract}
Osnovni cilj ovog istraživanja bio je utvrdivanje prediktivne vrednosti osobina ličnosti modela velikih pet za ukupno zadovoljstvo poslom, kao $i$ za devet aspekata zadovoljstva poslom merenih skalom Job Satisfaction Survey. Pored osobina ličnosti, kao kategorijalni prediktori ispitivane su varijable pol $i$ staž na univerzitetu. Uzorak ispitanika činili su nastavnici i saradnici zaposleni na Univerzitetu u Novom Sadu i Beogradu, ukupno njih 300. Na osnovu dobijenih rezultata možemo zaključiti da se kao značajni prediktori ukupnog zadovoljstva poslom izdvajaju osobine prijatnost $i$ neuroticizam, dok se kategorijalne varijable nisu pokazale kao značajni prediktori. Za predikciju zadovoljstva pojedinim aspektima posla izdvajaju se prijatnost, savesnost $i$ neuroticizam, $i$ to: prijatnost za aspekte napredovanje, rukovodenje, priroda posla, komunikacije i saradnici, savesnost $z a$ aspekte saradnici, beneficije $i$ nagradivanje $i$ neuroticizam za aspekte rukovodenje, priroda posla, komunikacije, saradnici, beneficije i nagradivanje. Kategorijalni prediktori nisu se izdvojili kao značajni. Aspekte zadovoljstva definisane kao plata $i$ priroda posla ne možemo predikovati na osnovu zadatih prediktora.
\end{abstract}

Ključne reči: zadovoljstvo poslom, aspekti zadovoljstva poslom, big five, osobine ličnosti, univerzitetski nastavnici i saradnici.

\footnotetext{
${ }^{1}$ Rad je deo projekta Psihološki aspekti društva u tranziciji - 149008 pod pokroviteljstvom Ministarstva za nauku i tehnološki razvoj

${ }^{2}$ Adresa autora: matanovic.j@gmail.com
} 


\section{Uvod}

Zadovoljstvo poslom, značajno drugačije od onoga kako ga mi danas definišemo, spominjali su još Frederik Vinslou Tejlor i Frenk Žilbret (F. W. Taylor and Gilbreth, 1911, prema Wright, 2006) dvadesetih godina prošlog veka, smatrajući da principi naučnog upravljanja značajno smanjuju količinu fizičkog napora neophodnog za izvršavanje radnih zadataka i tako ujedno utiču na psihičko zadovoljstvo ljudi. Naime, prema principima naučnog upravljanja, radnik treba da radi ono što mu se kaže, da postiže najbolje moguće rezultate u najkraćem mogućem vremenu, i za to će biti pošteno plaćen. Tejlorova osnovna pretpostavka bila je da, ukoliko pojedinac prihvati osnovna načela naučnog upravljanja kao sopstvena, uz najmanje moguće ulaganje napora postizaće najbolje rezultate i dobijati najvišu moguću platu, a to će voditi visokom zadovoljstvu poslom kod pojedinca. Dakle, prema ovoj teoriji, novac, tj. plata je odgovorna za razvoj zadovoljstva poslom kod pojedinaca.

Na temeljima Hotorn studije razvila se Doktrina ljudskih odnosa koja ukazuje na značaj socijalne motivacije za rad, te da zadovoljstvo poslom predstavlja socijalni stav koji, pored kognitivnog i konativnog aspekta, čine i emocije, tj. osećanja (Wright, 2006).

Istorijski gledano, uvođenje zadovoljstva poslom, (job satisfaction), u naučne krugove učinio je Hopok (Hoppock, 1935, prema Wright, 2006) koji smatra da je zadovoljstvo poslom

kombinacija psiholoških i fizioloških okolnosti, kao i okolnosti okruženja koje uzrokuju da zaposleni kaže: ,ja sam zadovoljan svojim poslom“. Danas u literaturi srećemo dva osnovna koncepta kada je u pitanju zadovoljstvo poslom. Prvi pristup je holistički, koji zadovoljstvo poslom smatra jednodimenzionalnim konstruktom. To je stav osobe prema poslu, jedno centralno osećanje vezano za posao koje se ne deli na pojedinačne aspekte. Drugi pristup zadovoljstvu poslom je aditivni pristup koji ovaj konstrukt posmatra kao višedimenzionalni. Prema ovom pristupu zadovoljstvo poslom čini zadovoljstvo pojedinim aspektima posla. Ono što osoba oseća prema poslu je suma zadovoljstava pojedinim aspektima posla.

Teorijska osnova ovog istraživanja je empirijski utemeljena teorija Pola Spektora (Spector, 1997) prema kojoj se zadovoljstvo poslom određuje kao „ono što osoba oseća prema svom poslu i različitim aspektima posla" (Spector, 1997, str. 2).

Mnoga istraživanja u oblasti industrijsko organizacijske psihologije ispituju vezu zadovoljstva poslom i pojedinih osobina ličnosti. Još ranih tridesetih go- 
dina prošlog veka naučnici su uvideli vezu između osobina ličnosti i zadovoljstva poslom. Vrlo često teorijska osnova se pronalazi u Big Five modelu. Model podrazumeva da se crte ličnosti mogu meriti pomoću upitnika za samoprocenu, da su stabilne u odraslom dobu, kao i da utiču na mišljenje, osećanja i ponašanja osobe (Đurić-Jočić i saradnici, 2004). Model Velikih pet čine dimenzije ličnosti definisane kao: ekstraverzija (extraversion), neuroticizam (neuroticism), prijatnost (agreeableness), savesnost (conscientiousness) i otvorenost ka iskustvu (openness to experience).

Fišer i Hana (Fisher and Hanna, 1931, prema Judge i saradnici, 2002) zaključili su da nezadovoljstvo poslom u velikoj meri nastaje kao rezultat emocionalne neprilagođenosti. Hopok (Hoppock, 1935, prema Judge i saradnici, 2002) je takođe pronašao značajnu korelaciju između emocionalne stabilnosti radnika i mere njihovog zadovoljstva poslom.

Brojna su istraživanja koja se bave odnosom osobina ličnosti modela Velikih pet i zadovoljstva poslom. Odličan pregled, kao i meta-analizu brojnih istraživanja nalazimo u radu Džadža i saradnika (Judge, Heller and Mount, 2002). Autori su u svoju meta-analizu uključili 163 nezavisna uzorka. Rezultati studije ukazuju da su tri od pet dimenzija modela značajni prediktori zadovoljstva poslom. Neuroticizam najsnažnije korelira sa zadovoljstvom poslom (.-29). Osobe koje imaju visok skor na neuroticizmu sklone su doživljavanju negativnih emocija. Ove rezultate potvrđuju i rezultati Furnama i Zakerla (1986) Smita i saradnika (1983) kao i Tokara i Subiča (1997) (sve prema Judge et al. 1999). Svi navedeni autori su u svojim istraživanjima potvrdili negativnu korelaciju između neuroticizma i zadovoljstva poslom. Džadž (Judge et al. 1999) takođe je potvrdio ovu vezu u svom istraživanju. Savesnost je sledeća osobina ličnosti iz modela Velikih pet koja značajno korelira sa zadovoljstvom poslom prema meta-analizi Džadža i saradnika (.26). Barik i Maunt (Barrick and Mount, 1991, prema Judge et al. 2002) potvrđuju pozitivnu korelaciju savesnosti i zadovoljstva poslom, pretpostavljajući da osobe koje imaju visok skor na savesnosti pokazuju dobre radne performanse, a ove opet dovode do zadovoljavajućeg priznanja za rad, samim tim i do većeg zadovoljstva poslom. Džadž (Judge et al. 1999) takođe ističe da je savesnost prediktor intrinzičnog poslovnog uspeha koji je operacionalizovan kao zadovoljstvo poslom. Treća osobina koja se pojavljuje kao značajan prediktor zadovoljstva poslom je ekstraverzija. Kako u meta-analizi Džadža i saradnika, tako i u brojnim drugim studijama (Furnam and Zacherl, 1986; Watson and Slack, 1993; Watson i Clark, 1997, sve prema Judge et al. 1999). Drugačije od ovih rezultata dobili su Džadž i saradnici (Judge et al. 1999) koji nisu pronašli značajnu vezu između ekstraverzije i zadovoljstva poslom. 
Faktori prijatnost i otvorenost ka iskustvu se nisu pokazali kao prediktori zadovoljstva poslom u meta-studiji Džadža i saradnika, međutim pojedini autori su dobili drugačije rezultate. MekRe i Kosta (McCrae and Costa 1991) su utvrdili da je prijatnost prediktor zadovoljstva poslom, to objašnjavajući time što su osobe koje imaju visok skor na ovom faktoru motivisane za postizanje visokog stepena emocionalne bliskosti sa svojim saradnicima, što doprinosi višem zadovoljstvu poslom.

Rezultati saopšteni u ovom članku deo su veće studije koja se bavila strukturom i determinantama zadovoljstva poslom univerzitetskih nastavnika i saradnika. Univerzitetski zaposlenici su izabrani za uzorak u ovom istraživanju zbog njihovog velikog značaja za zajednicu, budući da se bave izuzetno važnim i društveno priznatim poslom, osposobljavanjem mladih stručnjaka za profesionalni rad, a poznato je da je zadovoljstvo poslom u pozitivnoj vezi sa produktivnošću, kao i da je optimalan nivo zadovoljstva poslom od velikog značaja za funkcionisanje organizacije.

Osnovni cilj ovog istraživanja bio je utvrđivanje prediktivne vrednosti osobina ličnosti, pola i staža na univerzitetu za nivo ukupnog zadovoljstva poslom, kao i za zadovoljstvo pojedinim aspektima posla.

\section{Metod}

\section{Uzorak i postupak}

Istraživanje je sprovedeno na ukupnom uzorku od 300 nastavnika i saradnika zaposlenih na Univerzitetu u Novom Sadu, (oko 80\% od celokupnog uzorka), i Univerzitetu u Beogradu, (oko 20\% od celokupnog uzorka). Prosečna starost ispitanika je 40 godina, a raspon godina se kreće od 22-65 godina. Uzorkom su obuhvaćeni nastavnici i saradnici koji su zaposleni na fakultetima različitih naučnih oblasti, (prirodno-matematička, društveno-humanistička, tehničkotehnološka, medicinska i oblast umetnosti). Takođe, ispitanici imaju različita zvanja, (asistent-pripravnik, tj. saradnik u nastavi, asistent, docent, vanredni i redovni profesor). 44\% uzorka činili su muškarci, a 56\% žene. Ispitivanje je sprovedeno u prvoj polovini 2009. godine, lično i putem elektronske pošte.

\section{Instrumenti}

Skala Job Satisfaction Survey (JSS, Spector, 1985) predstavlja skalu stavova kojom se procenjuje devet aspekata zadovoljstva poslom. JSS je šestostepena 
skala Likertovog tipa, sadrži 36 ajtema. Na osnovu podataka dobijenih putem ove skale možemo izračunati deset nezavisnih skorova. Devet skorova čini rezultate ispitanika na pojedinačnim subskalama, a deseti skor je sumacioni skor ispitanika na svim ajtemima i predstavlja opštu meru zadovoljstva poslom. Devet aspekata zadovoljstva poslom koje meri ova skala su: plata, napredovanje, rukovođenje, beneficije, nagrađivanje, radne procedure, saradnici, priroda posla i komunikacije. Pouzdanost skale je merena $\alpha$ koeficijentom iznosi .91 a pouzdanost pojedinih subskala kreće se između .60 i .82 .

The Big Five Inventory (BFI, John, Donahue \& Kentle, 1991), je petostepena skala Likertovog tipa kojom se operacionalizuju osobine ličnosti modela velikih pet. Skalu čini 44 tvrdnje, sa pet subskala: ekstraverzija, prijatnost, savesnost, neuroticizam, otvorenost ka iskustvu. Pouzdanost ove skale iznosi $\alpha=0,83$.

Pored ova dva instrumenta, bateriji testova priključene su i varijable pol i staž na univerzitetu. Varijabla staž na univerzitetu operacionalizovana je kao kategorijalna varijabla koja predstavlja ukupni radni staž ispitanika kao zaposlenih na Univerzitetu koji imaju do trenutka istraživanja, i ima pet kategorija: 1 - 5, $6-10,11-15,16-20,21-30$ godina i više.

Radi utvrđivanja prediktora ukupnog zadovoljstva poslom na podacima je sprovedena analiza kovarijanse. Za utvrđivanje značajnih prediktora za pojedine aspekte zadovoljstva poslom najpre je sprovedena multivarijatna analiza kovarijanse, a zatim za svaki od aspekata posla analiza varijanse. Pored osobina ličnosti koje su bile kontinuirani prediktori, kao kategorijalni prediktori korišćeni su pol i staž na univerzitetu.

\section{Rezultati}

U tabeli 1 nalaze se univarijatni efekti prediktora za ukupno zadovoljstvo poslom.

Sprovedena analiza ukazuje na to da se kao značajni prediktori ukupnog zadovoljstva poslom izdvajaju osobine prijatnost i neuroticizam.

Da bi utvrdili da li su pojedine osobine ličnosti, kao i varijable pol i staž na univerzitetu značajni prediktori devet aspekata zadovoljstva poslom sprovedena je multivarijatna analiza kovarijanse. 
Tabela 1: Univarijatni efekti prediktora za ukupno zadovoljstvo poslom

\begin{tabular}{lcccccc}
\hline \multicolumn{1}{c}{$\mathbf{R = . 4 6} \mathbf{R}^{\mathbf{2}}=\mathbf{2 1} \mathbf{F}=\mathbf{1 . 9 4} \mathbf{p = . 0 0}$} & & & \\
\hline & $\mathbf{S S}$ & $\mathbf{d f}$ & $\mathbf{M S}$ & $\mathbf{F}$ & $\mathbf{p}$ & Beta \\
\hline Ekstraverzija & 51.96 & 1 & 51.96 & .10 & .76 & .02 \\
Prijatnost & $\mathbf{6 0 4 9 . 0 1}$ & $\mathbf{1}$ & $\mathbf{6 0 4 9 . 0 1}$ & $\mathbf{1 1 . 2 3}$ & $\mathbf{. 0 0}$ & $\mathbf{. 2 4}$ \\
Savesnost & 1265.35 & 1 & 1265.35 & 2.35 & .13 & -.11 \\
Neuroticizam & $\mathbf{5 2 0 6 . 7 8}$ & $\mathbf{1}$ & $\mathbf{5 2 0 6 . 7 8}$ & $\mathbf{9 . 6 7}$ & $\mathbf{. 0 0}$ & $\mathbf{- . 2 1}$ \\
otvorenost ka iskustvu & 155.40 & 1 & 155.40 & .29 & .59 & .04 \\
Pol & 352.16 & 1 & 352.16 & .65 & .42 & .06 \\
staž na univerzitetu & 295.45 & 1 & 295.45 & .55 & .46 & .07 \\
\hline
\end{tabular}

Tabela 2:MANCOVA - značajnost modela

\begin{tabular}{lllllllll}
\hline & $\mathbf{R}$ & $\mathbf{R}^{2}$ & $\begin{array}{l}\text { prilago- } \\
\text { đeni } \mathbf{R}^{2}\end{array}$ & \multicolumn{1}{l}{ SS } & df & MS & F & P \\
\cline { 2 - 8 } Plata & $\mathbf{0 . 4 6}$ & $\mathbf{0 . 2 1}$ & .10 & $\mathbf{1 2 9 1 . 8 4}$ & $\mathbf{3 5}$ & $\mathbf{3 6 . 9 1}$ & $\mathbf{1 . 9 4}$ & .00 \\
napredovanje & $\mathbf{0 . 4 2}$ & $\mathbf{0 . 1 8}$ & .07 & $\mathbf{7 8 9 . 8 0}$ & $\mathbf{3 5}$ & $\mathbf{2 2 . 5 7}$ & $\mathbf{1 . 5 9}$ & .02 \\
rukovođenje & $\mathbf{0 . 5 0}$ & $\mathbf{0 . 2 5}$ & .15 & $\mathbf{1 3 2 1 . 3 9}$ & $\mathbf{3 5}$ & $\mathbf{3 7 . 7 5}$ & $\mathbf{2 . 5 1}$ & .00 \\
beneficije & $\mathbf{0 . 4 4}$ & $\mathbf{0 . 2 0}$ & .09 & $\mathbf{1 0 5 7 . 7 5}$ & $\mathbf{3 5}$ & $\mathbf{3 0 . 2 2}$ & $\mathbf{1 . 8 2}$ & .00 \\
nagrađivanje & $\mathbf{0 . 4 3}$ & $\mathbf{0 . 1 8}$ & .07 & $\mathbf{1 0 9 1 . 1 0}$ & $\mathbf{3 5}$ & $\mathbf{3 1 . 1 7}$ & $\mathbf{1 . 6 6}$ & .01 \\
Radne & 0.38 & 0.14 & .03 & 735.27 & 35 & 21.01 & 1.24 & .18 \\
procedure & & & & & & & & \\
saradnici & $\mathbf{0 . 4 7}$ & $\mathbf{0 . 2 2}$ & .11 & $\mathbf{8 7 0 . 8 8}$ & $\mathbf{3 5}$ & $\mathbf{2 4 . 8 8}$ & $\mathbf{2 . 0 6}$ & .00 \\
priroda posla & $\mathbf{0 . 5 9}$ & $\mathbf{0 . 3 4}$ & .25 & $\mathbf{1 0 6 2 . 9 0}$ & $\mathbf{3 5}$ & $\mathbf{3 0 . 3 7}$ & $\mathbf{3 . 8 6}$ & .00 \\
komunikacije & $\mathbf{0 . 4 3}$ & $\mathbf{0 . 1 9}$ & $\mathbf{. 0 8}$ & $\mathbf{8 8 0 . 4 4}$ & $\mathbf{3 5}$ & $\mathbf{2 5 . 1 6}$ & $\mathbf{1 . 7 0}$ & .01 \\
\hline
\end{tabular}

Tabela 3: Multivarijatni efekti prediktora

\begin{tabular}{lccc}
\hline & Wilks' Lambda & F & p \\
\hline ekstraverzija - E & .946 & 1.596 & .12 \\
prijatnost - P &. $\mathbf{8 9 3}$ & $\mathbf{3 . 3 4 5}$ & $\mathbf{. 0 0}$ \\
savesnost - S & .922 & $\mathbf{2 . 3 7 0}$ & $\mathbf{. 0 1}$ \\
neuroticizam - N & .932 & $\mathbf{2 . 0 2 7}$ & $\mathbf{. 0 4}$ \\
otvorenost ka iskustvu - O & .943 & 1.675 & .10 \\
Pol & .941 & 1.736 & .08 \\
staž na univerzitetu - SU & .982 & .504 & .87 \\
\hline
\end{tabular}


Kao značajni prediktori pojedinih aspekata zadovoljstva poslom izdvajaju se osobine prijatnost, savesnost i neuroticizam. Kategorijalni prediktori nisu značajni.

Značajni prediktori pojedinih aspekata zadovoljstva poslom navedeni su $\mathrm{u}$ tabeli broj 4 .

Tabela 4: Značajnost prediktora za predikciju pojedinih aspekata zadovoljstva poslom

\begin{tabular}{|c|c|c|c|c|c|c|c|}
\hline & $\mathbf{E}$ & $\mathbf{P}$ & $\mathbf{N}$ & $\mathbf{S}$ & 0 & POL & SU \\
\hline napredovanje & & $\begin{array}{r}\mathrm{F}=3.98 \\
\mathrm{p}=.05 \\
\text { Beta }=.15\end{array}$ & & & & & \\
\hline rukovođenje & & $\begin{array}{r}\mathrm{F}=10.76 \\
\mathrm{p}=.00 \\
\text { Beta }=.23\end{array}$ & $\begin{array}{r}\mathrm{F}=5.26 \\
\mathrm{p}=.02 \\
\text { Beta }=-.15\end{array}$ & & & & \\
\hline beneficije & & & $\begin{array}{r}\mathrm{F}=8.63 \\
\mathrm{p}=.00 \\
\text { Beta }=-.20\end{array}$ & $\begin{array}{r}\mathrm{F}=5.01 \\
\mathrm{p}=.03 \\
\text { Beta }=-.16\end{array}$ & & & \\
\hline nagrađivanje & & & $\begin{array}{r}\mathrm{F}=9.16 \\
\mathrm{p}=.00 \\
\text { Beta }=-.21\end{array}$ & $\begin{array}{r}\mathrm{F}=6.10 \\
\mathrm{p}=.01 \\
\text { Beta }=-.18\end{array}$ & & & \\
\hline saradnici & & $\begin{array}{r}\mathrm{F}=27.52 \\
\mathrm{p}=.00 \\
\text { Beta }=.38\end{array}$ & $\begin{array}{r}\mathrm{F}=4.88 \\
\mathrm{p}=.03 \\
\text { Beta}=-.15\end{array}$ & $\begin{array}{r}\mathrm{F}=6.21 \\
\mathrm{p}=.01 \\
\text { Beta }=-.17\end{array}$ & & & \\
\hline priroda posla & & $\begin{array}{r}\mathrm{F}=9.19 \\
\mathrm{p}=.00 \\
\text { Beta }=.20\end{array}$ & $\begin{array}{r}\mathrm{F}=4.15 \\
\mathrm{p}=.04 \\
\text { Beta}=-.13\end{array}$ & & & & \\
\hline komunikacije & & $\begin{array}{r}\mathrm{F}=6.41 \\
\mathrm{p}=.01 \\
\text { Beta }=.19\end{array}$ & $\begin{array}{r}\mathrm{F}=4.70 \\
\mathrm{p}=.03 \\
\text { Beta }=-.15\end{array}$ & & & & \\
\hline \multicolumn{8}{|l|}{ plata } \\
\hline $\begin{array}{l}\text { radne } \\
\text { procedure }\end{array}$ & & & & & & & \\
\hline
\end{tabular}

Iz tabele broj 4 možemo zaključiti da se za predikciju aspekta posla definisanog kao napredovanje izdvojila se osobina prijatnost. Kao značajni prediktori aspekata posla rukovođenje, saradnici, priroda posla i komunikacije izdvojile su se osobine prijatnost i neuroticizam. Beta koeficijenti ukazuju da će osobe sa višim rezultatima na skali prijatnosti i nižim rezultatima na skali neuroticizma razviti viši nivo zadovoljstva ovim aspektima posla. Aspek zadovoljstva definisan kao saradnici možemo predvideti na osnovu osobine savesnost, koja je značajna i za predikciju aspekta beneficije i nagrađivanje. 
Varijable pol i staž na univerzitetu nisu se izdvojile kao značajne za predikciju zadovoljstva pojedinim aspektima posla. Takođe, možemo zaključiti da na osnovu osobina ličnosti modela velikih pet nismo mogli predvideti nivo zadovoljstva aspektima plata i radne procedure.

\section{Diskusija}

Ovim istraživanjem pokušali smo da utvrdimo potencijalne prediktore ukupnog zadovoljstva poslom i zadovoljstva njegovim aspektima iz grupe dimenzija ličnosti modela velikih pet, kao i na osnovu pola i staža na univerzitetu. Specifičan uzorak činili su univerzitetski nastavnici i saradnici.

Kao značajni prediktori ukupnog zadovoljstva poslom izdvojile su se osobine prijatnost i neuroticizam, gde će osobe sa višim skorovima na skali prijatnosti razviti više zadovoljstvo poslom, dok će osobe sa visokim skorovima na skali neuroticizma razviti niže ukupno zadovoljstvo poslom. Osobe sa visokim skorovima na skali prijatnosti dobrodušne, saradljive, neguju prijateljske odnose sa drugim ljudima, norme usvajaju iz više izvora. Lako će se uklopiti u radnu sredinu, a budući da su prijateljski raspoložene prema drugim ljudima, vrlo je verovatno da neće imati problema u odnosima sa saradnicima i iz zadovoljstva saradnicima će razviti visoko ukupno zadovoljstvo poslom.

Ono što je interesantno je, da se u radovima stranih autora, prijatnost uglavnom ne pojavljuje kao značajan prediktor zadovoljstva poslom, osim kod MekRea i Koste, (McCrae and Costa, 1991), koji su ovu vezu objasnili visokom motivisanošću osoba koje imaju visok rezultat na skali prijatnosti za postizanje osećanja emocionalne bliskosti sa saradnicima na poslu što dovodi do višeg zadovoljstva poslom.

Rezultat koji je zajednički za ispitanike koji su učestvovali u ovom istraživanju i u pojedinim drugim istraživanjima (Judge et al. 1999, 2002) je onaj koji ukazuje da je dimenzija neuroticizam značajan prediktor niskog zadovoljstva poslom. Objašnjenje leži u činjenici da su osobe koje imaju visok skor na neuroticizmu sklone doživljavanju negativnih emocija u svim sferama svog života, pa tako i u radnom okruženju. Ove osobe se lako naljute, često se upuštaju u konflikte sa drugima, burno reaguju, a to su ponašanja koja nisu u skladu sa socijalnim normama na radnom mestu. Osobe sa visokim rezultatom na skali neuroticizma vrlo verovatno imaju česte konfliktne situacije na radnom mes$\mathrm{tu}$, te su iz tog razloga sklone razvijanju nezadovoljstva poslom. Nasuprot njima, emocionalno stabilne osobe, uspešne u regulaciji sopstvenih i emocija drugih ljudi, prema rezultatima dobijenim u ovom istraživanju, razviće više zadovoljstvo poslom. 
Kao značajne za predikciju pojedinih aspekata zadovoljstva poslom izdvojile su se osobine prijatnost, savesnost i neuroticizam. Kao značajan prediktor aspekta napredovanje izdvojila se osobina prijatnost, koja je značajna i za predikciju aspekata rukovođenje, priroda posla, komunikacije i saradnici. Osobe koje imaju visoke skorove na osobini prijatnost razviće više zadovoljstvo navedenim aspektima zadovoljstva poslom. Saradljiva i dobrodušna osoba, koja teži harmoniji po svaku cenu je osoba koja će biti zadovoljna sa onim što joj se pruža, samo da ne bi ulazila u konflikte, pa će iz tog razloga osobe sa visokim skorovima na prijatnosti imati visoke skorove i na aspektu posla napredovanje. Osobe koje imaju izrazito visoke skorove na skali prijatnosti prihvataju norme bez obzira da li su u skladu sa njihovim shvatanjima, te će iz tog razloga, vrlo verovatno, osobe razviti visoko zadovoljstvo rukovođenjem, jer će smatrati da treba da se ponašaju u skladu sa zahtevima svog rukovodioca, prihvatiće njegove norme, a budući da im je harmonija u međuljudskim odnosima bitnija od svega drugog prihvatiće svoje rukovodioce idealistički, bez kritičke procene te će razviti visok nivo zadovoljstva rukovođenjem. Prijatna i saradljiva osoba teži harmoniji i međuljudskoj bliskosti, pretpostavka je da će joj većina saradnika biti dobra, te će razviti visoko zadovoljstvo na ovom aspektu.

Neuroticizam je osobina koja se izdvaja kao najčešći prediktor zadovoljstva pojedinim aspektima posla. Osobe sa visokim skorom na ovoj skali razviće niže zadovoljstvo aspektima posla definisanim kao rukovođenje, priroda posla, komunikacije, saradnici, beneficije i nagrađivanje. Osoba koja ima visok skor na ovoj skali u organizacijskom kontekstu se teže prilagođava, često je u sukobu sa saradnicima i autoritetom i značajno duže se oporavlja od stresa od osoba koje imaju nizak skor na ovoj skali. Vrlo lako ulazi u konflikte, sklona je burnim reakcijama i doživljavanju negativnih emocija u svim sferama života, pa je logično da će i u organizaciji biti sklona negativnim emocijama, te će razviti nisko zadovoljstvo poslom.

Zadovoljstvo aspektima posla saradnici, beneficije i nagrađivanje možemo predvideti na osnovu skora na skali savesnosti. Ovaj rezultati je u suprotnosti sa rezultatima pojedinih autora (Judge et al. 1999, 2002) čiji rezultati idu u prilog pozitivnoj vezi osobine savesnosti i zadovoljstva poslom. Osobe koje imaju visok skor na ovoj skali, prema rezultatima ovog istraživanja, imaće niže zadovoljstvo navedenim aspektima posla. Osoba koja ima visok skor na savesnosti vrlo je uporna, istrajna u ostvarivanju svojih ciljeva, odgovorna i ima visok motiv postignuća. Objašnjenje našeg nalaza možemo pronaći u Adamsovoj teoriji pravednosti (Adams and Freedman, 1976, prema Čukić, 2005). Naime, osoba sa visokim skorom na osobini savesnost, pretpostavljamo, želi da bude adekvatno nagrađena, materijalnim i nematerijalnim nagradama, smatra 
da je mnogo truda uložila, i moguće je da percipira nepravednost odnosa sopstvenih ulaganja i dobiti i ulaganja i dobiti drugih u organizaciji, te iz tog razloga razvija nisko zadovoljstvo ovim aspektima posla. Takođe pretpostavka je da je osoba sa visokim skorom na skali savesnosti orijentisana više na individualni, a manje na timski rad, te razvija niži nivo zadovoljstva na aspektu zadovoljstva saradnici. Moguće je da ih percipira kao pretnju u dostizanju svojih ciljeva u organizaciji. Interesantno je da se osobina ekstraverzije nije pokazala značajnom za predikciju zadovoljstva poslom, iako autori koji su se bavili ovom problematikom nju izdvajaju kao jednog od značajnih prediktora (Judge et al. 1999, 2002). Aspekte posla plata i radne procedure nismo mogli predvideti na osnovu zadatih prediktora. Što se tiče kategorijalnih prediktora, nisu se pokazali značajnim.

\section{Zaključak}

Ovim istraživanjem utvrđene su osobine ličnosti prediktori zadovoljstva poslom. Osobine prijatnost, savesnost i neuroticizam su značajne za predikciju zadovoljstva poslom i njegovim pojedinim aspektima. Osobe koje imaju visoke skorove na skalama neuroticizma i savesnosti razviće nisko zadovoljstvo poslom i njegovim pojedinim aspektima, dok će osobe sa visokim skorovima na skali prijatnosti razviti više zadovoljstvo poslom. Ovo istraživanje sprovedeno je na specifičnom uzorku univerzitetskih nastavnika i saradnika, te bi bilo interesantno proveriti prediktivnu vrednost ovih varijabli na reprezentativnom uzorku.

\section{Reference}

Čukić, B. (2005). Organizaciono ponašanje u ulogama i grupama. Kruševac: Fakultet za industrijski menadžment, Izdavački centar za industrijski menadžment plus.

Đurić-Jočić, D. Džamonja-Ignjatović, T. i Knežević, G. (2004). NEO PI-R, primena i interpretacija. Beograd: Centar za primenjenu psihologiju.

Ilies, R. and Judge, T. (2003). On the heritability of job satisfaction: The mediating role of personality. Journal of Applied Psychology, 88, 750-759.

John, O. P., Donahue, E. M., Kentle, R. L. (1991). The Big Five Inventory - Versions 44 and 54. Berkley, CA: University of California, Berkley, Institute of Personality and Social Research. 
Judge, T. A. Higgins, C. A. Thoresen, C. J. and Barrick, M. R. (1999). The Big Five personality traits, general mental ability, and career success across the life span. Personnel Psychology, 52, 621-652.

Judge, T. Heller, D. and Mount, M. (2002). Five-factor model of personality and job satisfaction: A meta-analysis. Journal of Applied Psychology, 87, 530-541.

McCrae, R. R., and. Costa, P. T. (1991). Adding liebe und arbeit: The full fivefactor model and well-being. Personality and Social Psychology Bulettin, $17,227-232$.

Spector, P. E. (1985). Measurement of human Service Staff Satisfaction: Development of the Job Satisfaction Survey. American Journal of Community Psychology, 13, 693-713.

Spector,P. E. (1997). Job Satisfaction: Application, Assessment, Causes and Consequences. Thousand Oaks, California, USA: Sage Publications.

Wright, Th. A. (2006). The emergence of job satisfaction in organizational behavior, A historical overview of the dawn of job attitude research. Journal of Management History, 12, 262-277. 


\section{Abstract}

\section{PERSONALITY TRAITS AS PREDICTORS OF JOB SATISFACTION}

Jelena Matanović

The main aim of this research was to establish whether personality traits of the big five model could be predictors of total job satisfaction and nine specific aspects of job satisfaction, measured by JSS. Other than the personality traits, as categorical predictors variables gender and length of employment time at the University were researched. The research included a sample of 300 university teachers and their assistants employed at the University of Novi Sad and University of Belgrade. Upon the given results, we can conclude that agreeableness and neuroticism are set aside as significant predictors of job satisfaction but categorical predictors were not significant. Satisfaction predictors as agreeableness, conscientiousness and neuroticism are separated in some aspects of job: agreeableness for aspect of promotion, supervision, nature of work, communication and co-workers, conscientiousness for aspects of co-workers, benefits and contingent rewards and neuroticism for supervision, nature of work, communication, co-workers benefits and contingent rewards. Categorical predictors were not significant. Aspects of satisfaction defined as pay and job nature can not be predicted upon the given predictors.

Keywords: job satisfaction, aspects of job satisfaction, big five, personality traits, university professors

Primljeno: 23.11.2009; prihvaćeno za štampu: 11.12.2009. 